\title{
CURRÍCULO ESCOLAR: UMA CONSTRUÇÃO HISTÓRICA, TEÓRICA E IDEOLÓGICA
}

\author{
Sandra Aparecida Pires Franco ${ }^{1}$ \\ Adrielly Rocateli ${ }^{2}$ \\ Pâmela Cristina Guslen Rufino dos Santos Barbosa ${ }^{3}$ \\ Daniella Caroline Rodrigues Ribeiro Ferreira ${ }^{4}$ \\ Adriana Regina de Jesus Santos ${ }^{5}$
}

\begin{abstract}
RESUMO: O presente estudo tem como objetivo compreender o conceito de currículo escolar tendo como parâmetro abordagens teóricas e metodológicas, tais como: acadêmica, humanista, tecnológica e reconstrucionista, a fim de identificar as influências culturais, ideológicas, políticas, econômicas e as relações de poder que permeiam a sua constituição e o quanto poderão refletir no âmbito educacional. Para o desenvolvimento desse estudo, fez-se o uso da pesquisa bibliográfica para o seguinte questionamento: Qual o conceito de currículo escolar e a abordagem teórica que permeiam o currículo escolar da sociedade brasileira do século XXI. A partir do estudo bibliográfico, compreende-se que o professor diante do atual contexto educativo e social do século XXI deve conhecer o processo de construção do currículo escolar e suas diferentes abordagens teóricas, pois estes nortearão os encaminhamentos pedagógicos no que se refere ao processo de ensino e aprendizagem e consequentemente na formação de mundo, de sociedade e de sujeitos que a escola almeja formar.
\end{abstract}

\footnotetext{
${ }^{1}$ Doutora em Letras pela Universidade Estadual de Londrina. Docente do Programa de Pós-Graduação em Educação da Universidade Estadual de Londrina (UEL). E-mail: sandrafranco26@hotmail.com

${ }^{2}$ Pedagoga. Mestranda em Educação no Programa de Pós-Graduação em Educação da UEL. E-mail: adrielly@uel.br

${ }^{3}$ Pedagoga. Mestranda em Educação no programa de Pós-graduação em Educação da UEL.

E-mail: pamela.guslen@gmail.com

${ }^{4}$ Pedagoga. Mestranda em Educação no programa de Pós-graduação em Educação da UEL.

E-mail: daniellacarolinef@gmail.com

${ }^{5}$ Mestre em Educação no programa de Pós-graduação em Educação da UEL. Docente da Universidade Estadual de Londrina e da Universidade Norte do Paraná. E-mail: adrianatecnologia@yahoo.com.br
} 
Palavras-chave: Educação. Currículo. Abordagens Teóricas.

\title{
SCHOOL CURRICULUM: A HISTORICAL, THEORETICAL AND IDEOLOGICAL CONSTRUCTION
}

\begin{abstract}
This study aims to understand the concept of school curriculum taking as a parameter theoretical and methodological approaches, such as: academic, humanist, technological and reconstructionist, in order to identify cultural, ideological, political, economic and relations of power that permeate its constitution and how much it may reflect in the educational field. For the development of this study, the bibliographic research was used for answer the following question: What is the concept of school curriculum and the theoretical approach that permeate the school curriculum of 21st century Brazilian society. From the bibliographic study, it is understood that the teacher facing the current educational and social context of the 21st century, should know the process of construction of the school curriculum and its different theoretical approaches, as these will guide the pedagogical guidelines regarding the process of teaching and learning and consequently in the formation of world, society and subjects that the school aims to form.
\end{abstract}

Keywords: Education. Curriculum. Theoretical Approaches.

\section{CURRÍCULO ESCOLAR: UNA CONSTRUCCIÓN HISTÓRICA, TEÓRICA E IDEOLÓGICA}

RESUMEN: Este estudio tiene como objetivo comprender el concepto de currículum escolar tomando como parámetro enfoques teóricos y metodológicos, tales como: académico, humanista, tecnológico y reconstruccionista, para identificar las relaciones culturales, ideológicas, políticas, económicas y de relaciones. de poder que impregna su constitución y cuánto puede reflejar en la educación. Para el desarrollo de este estudio, la investigación bibliográfica se utilizó para contestar a la siguiente pregunta: ¿Cuál es el concepto de currículum escolar y el enfoque teórico que impregna el currículum escolar de la sociedad brasileña del siglo XXI? A partir del estudio bibliográfico, se entiende que el docente que enfrenta el contexto educativo y social actual del siglo XXI debe conocer el proceso de construcción del currículo escolar y sus diferentes enfoques teóricos, ya que estos guiarán las pautas pedagógicas con respecto al proceso de 
enseñanza y aprendizaje y, en consecuencia, en la formación del mundo, de la sociedad y de los sujetos que la escuela pretende formar.

Palabras clave: Educación. Plan de estudios. Enfoques teóricos.

O presente estudo é resultado de reflexões e discussões que foram proporcionadas por meio da disciplina: O Currículo escolar e suas interfaces teórica e metodológica, vinculada ao Programa de Pós-Graduação em Educação da Universidade Estadual de Londrina. Sendo assim, tem como objetivo compreender o conceito de currículo escolar tendo como parâmetro as abordagens teóricas e metodológicas, tais como: acadêmico, humanista, tecnológico e reconstrucionista, a fim de identificar as influências culturais, ideológicas, políticas, econômicas e as relações de poder que permeiam a sua constituição e o quanto poderão refletir no âmbito educacional.

Para o desenvolvimento do referido estudo, utilizamos da descrição, da compreensão, do significado, interpretando os fenômenos históricos e teóricos do conceito de currículo escolar. Isso posto, utilizamos como aporte teórico em nosso ensaio teórico as obras dos seguintes autores: Sacristán (1999), Moreira (1990) e Goodson (1995) para entendermos os conceitos e o contexto do currículo e suas interfaces com o poder, a ideologias e cultura; no que se refere ao currículo escolar e seus desafios na sociedade, apoiamo-nos nas pesquisas de Martins (2004) e Apple (2000) para elucidar a relação entre currículo e a pedagogia crítica, tendo como premissa a análise relacional e situacional envolvendo os aspectos curriculares, ideológicos, políticos, sociais e culturais.

Justifica-se a necessidade de compreendermos melhor sobre currículo e educação escolar e suas implicações no processo de ensino e aprendizagem por 
entender que a construção da proposta curricular escolar define o tipo de sociedade que se pretende formar. Para tanto, serão selecionados os saberes conceituais, procedimentais e atitudinais do conceito de currículo. Entretanto, dependendo da proposta em que o currículo escolar é pensado, este poderá ter um desenho curricular fragmentado, não considerando a perspectiva crítica em educação que tem como princípio a contextualização dos saberes. Contribuindo com essa reflexão Martins (2004, p. 31-32) afirma que:

No currículo escolar descontextualizado não importa se há saberes; se há dores e delícias; se há alegrias e belezas. A educação que continua sendo "enviada" por esta narrativa hegemônica, se esconde por trás de uma desculpa de universalidade dos conhecimentos que professa, e sequer pergunta a si própria sobre seus próprios enunciados, sobre seus próprios termos, sobre porque tais palavras e não outras, porque tais conceitos e não outros, porque tais autores, tais obras e não outras. Esta narrativa não se pergunta sobre os próprios preconceitos que distribui como sendo seus "universais". Desde aí o que se pretende é, portanto, colocar em questão estes universais. O que está por trás da ideia de "Educação para a convivência com o Semi-Árido" é, antes de qualquer coisa a defesa de uma contextualização da educação, do ensino, das metodologias, dos processos.

É nesse sentido, que se compreende o currículo como uma concepção política e culturalmente relacionado com o contexto dinâmico da sociedade, sendo assim, para uma melhor compreensão discorreremos a seguir o conceito e o contexto do currículo e suas respectivas abordagens teórico e metodológica.

\section{Reflexões iniciais sobre currículo}

Tendo como parâmetro a sociedade contemporânea, pensamos em um homem como um ser histórico e refletimos também o currículo que o atenderá. Para isso se 
faz necessário entendermos os conceitos, o contexto do currículo e suas interfaces com o poder, ideologias e cultura. Dessa forma, consideramos extremamente importante a reflexão acerca do currículo escolar e suas diferentes abordagens, pois pensar acerca dessa temática, significa entender o contexto social e educacional, ou seja, é notório perceber que a sociedade contemporânea vivencia um contexto social aligeirado. De acordo com Bauman (2007), esse contexto pode ser caracterizado como uma sociedade líquida, na qual temos a impressão que o sujeito se movimenta cotidianamente, no entanto a impressão que temos é que corremos sob uma superfície de camada bem fina de gelo, e tememos que se pararmos poderemos afundar, por isto corremos o tempo todo, no entanto não sabemos por que corrermos?, a favor de quem corremos? e contra que corremos?

Diante disso, entendemos que o ritmo da sociedade contemporânea não permite o pensar e esta falta de pensamento está presente também no contexto deducional. Nesse sentido, este ensaio teórico tem como premissa provocar o pensar acerca do currículo, pois ao refletir sobre, estaremos consequentemente analisando a sociedade como um todo, já que é por meio do currículo que podemos pensar um projeto de nação por meio da educação.

Contribuindo com essa reflexão Goodson (1995), afirma que pensar o currículo é pensar as formas de organização de uma sociedade, pois este é derivado da palavra latina currere, que significa correr, curso, carreira, e o seu significado se refere ao modo, à forma, ao local e ao que ocorre no percurso efetuado. Nesse sentido, conforme apontamentos de Apple (2000), o currículo escolar é a expressão de todo um equilíbrio de pensamentos e interesses que serão transmitidos sobre o sistema educativo, em um determinado momento histórico. 
Portanto, o conceito de currículo escolar vem sendo modificado durante a história de acordo com cada ideologia presente em sua época de formulação, do tipo de cultura e das relações de poder intrinsecamente ligadas a uma determinada sociedade (Apple, 2000). Para Young (2009), ao refletir sobre currículo escolar é importante pensar que em sua elaboração ocorre uma construção, um tipo de público social, que se torna primordial para analisar os valores e interesses da sociedade e estas características serão dimensionadas de acordo com as abordagens curriculares, pois estas são ancoradas por pressupostos teóricos e metodológicos que têm como premissa uma concepção de mundo, sociedade e de formação humana, que poderá ter sustentação teórica em uma perspectiva tradicional ou crítica, como veremos a seguir.

\section{As abordagens curriculares e suas implicações no campo da formação humana}

A construção de um currículo escolar é um processo social, cognitivo e cultural, no qual estão ligados os fatores lógicos, epistemológicos, intelectuais e os determinantes sociais que o compõem, como o poder, os interesses da sociedade, tanto no coletivo como individuais. Diante das contribuições apresentadas, nota-se o quanto o currículo escolar foi e ainda está se modificando ao longo da história, de acordo com a abordagem e teoria curricular de cada um. As influências das correntes de pensamentos que orientaram a configuração do currículo escolar tiveram origem no começo dos tempos modernos, na Europa, surgindo para atender as necessidades da burguesia, que estava sendo constituída naquele período histórico. Com essas 
características de sociedade, o currículo escolar surgiu de uma maneira sistematizada e para atender aos grupos no começo do século XVIII, uma vez que, nessa época, os comerciantes perceberam a necessidade que tinham de saber ler, escrever e demonstrar os seus raciocínios.

A partir desse momento começou o modelo de currículo, com características que não tinham como objetivo formar em nenhum grau de ensino. $O$ seu único objetivo era preparar os alunos para a nova ordem que estava sendo estabelecida e que precisava de uma demanda de alunos que praticassem a leitura e fizessem o uso da escrita. Determinou-se então, que era fundamental à formação comum e de técnicas básicas. Tal motivação levou à ampliação do currículo escolar que ocorreu em função da necessidade ideológica do liberalismo que tinha o intuito de fazer que todos se situassem em relação ao conjunto dos fatores naturais e sociopolíticos da época.

Conforme Moreira (1990), os séculos XIX, XX e XXI foram marcados pela luta da universalização da escola para todos, tanto para a sociedade urbana quanto para a sociedade rural. Com base nesse contexto, o fator da economia fez-se importante para influenciar nas mudanças de currículo escolar e de estrutura nas organizações do ambiente escolar, tanto a economia, como os conceitos ideológicos, fizeram parte deste cenário.

O pensamento e reflexões acerca do currículo escolar no Brasil tiveram início, segundo Moreira e Silva (1997), a partir da década de 1920 e 1930, tendo como base diferentes teorias tais como as influências do filósofo John Dewey, que critica o currículo escolar tradicional de ensino, com ideias de um currículo escolar voltado para uma base progressivista. Destaca-se que até esse momento histórico, o que predominava no currículo escolar eram as influências dos conteúdos escolares 
baseados na concepção jesuítica de ensino, com uma visão tradicional.

Os sociólogos Durkheim (2008) e Comte (1970) também contribuíram para acentuar o caráter enciclopédico do currículo escolar no Brasil, dando ênfase nas disciplinas que na época trabalhavam com Educação Moral e Cívica, Geometria, Português e Matemática, discussões que caminhavam sempre para um progresso e ordem de uma determinada sociedade. Mas, um fator que abalou significativamente a sociedade, foi a Primeira Guerra Mundial, e as crises econômicas do século XX e XXI na quais a educação, diante deste contexto, passou a ser proposta como o mais poderoso instrumento de reconstrução da sociedade, como as temáticas de política e moral para se pensar no bem-estar coletivo.

Nesse cenário, o indivíduo se tornou um ser de inúmeras influências no ambiente social, em que se defendeu que a formação deveria ocorrer somente em sala de aula, enfatizando a escola como uma comunidade fundamental para manter a ordem. No campo da educação, tanto as correntes renovadoras europeias, quanto as norte-americanas tinham como parâmetro a escola primária com uma educação que não fosse pensada somente para transmitir as matérias de ensino e sim também para ajudar em seus processos de desenvolvimento, sendo estimuladas da melhor maneira, a fim de buscar um coletivo diante da sociedade.

Baseando-se em uma educação alimentada pela filosofia pragmática norteamericana, pode-se citar as grandes influências de John Dewey, que tinha a visão de homem como um organismo que é modificado dependendo do seu ambiente e podendo se refazer constantemente, sofrendo assim modificações e podendo fazer também intervenções para seu próprio benefício. Surgiu, então, um modo de auxiliar nesse processo de transformação, que se faz por meio da cultura, na qual era 
necessário também preparar os jovens para o futuro e condições que ainda desconhecia. Esse modo de pensar preparava o aluno para as situações adversas do cotidiano e para aquilo que ele iria enfrentar futuramente. Dewey (1959) aponta que o conhecimento é o elemento primordial de um instrumento de conduta, intrinsecamente ligado com a função do pensamento que seria de controlar e modificar o mundo de acordo com suas necessidades humanas.

Pode-se dizer que as primeiras ideias de Dewey chegaram no Brasil no início do século XX, por intermédio de Anísio Teixeira, e a partir da década de 1930 que a educação e o currículo escolar passaram a ser discutidos entre os intelectuais, e havia crítica aos princípios cristãos. As relações, com o decorrer do tempo entre os católicos e escolanovistas ficaram complicadas, quando por meio dos Manifestos dos Pioneiros da Educação Nova, principalmente quando colocaram no documento que a igreja católica via sua atitude como certa heresia, como em colocavam e defendiam que era dever do estado tornar a educação obrigatória, pública e gratuita para todos (MOREIRA, 1990).

O Manifesto dos Pioneiros da Escola Nova foi um movimento extremamente importante para a História da Educação e a partir dessa discussão abriu-se a possibilidade de discutir uma educação que fosse pública e gratuita para todos, por meio das reformas educacionais. O currículo escolar partindo do pressuposto tinha como finalidade desenvolver na criança as habilidades de observar, pensar, julgar, criar, decidir e agir.

A interação entre escola e sociedade foi bem mais explorada do que nas reformas anteriores, rompendo assim com a escola tradicional. A partir de 1970, ocorreu um marco na história do currículo, em que diversos educadores brasileiros 
foram influenciados por várias abordagens teóricas, com diferentes concepções, teorias, tais como: psicológicas com fundamentos no behaviorismo, teorias funcionalistas, e nessa mesma época, estudos críticos (norte-americano e europeu), que faziam reflexões acerca das desigualdades entre as pessoas de diferentes classes sociais, a distribuição completamente desigual do conhecimento para a classe social inferior e o controle social da transmissão cultural.

Diante dos apontamentos de Moreira (1990), que cita Paulo Freire como um dos principais teóricos dessa abordagem, defendia em seus pensamentos que a educação devia conscientizar os oprimidos acerca de sua realidade social, capacitando para refletir sobre sua vida. Uma de suas propostas era a de superar o currículo escolar tradicional, completamente dissociado do cotidiano e ir para um currículo escolar de cunho crítico.

Conforme o cenário, pode-se perceber que a construção curricular no Brasil não ocorreu somente com um tipo de ideologia, um tipo de cultura, mas sofreu várias influências de tendências, objetivos e interesses diferentes. É nesse viés em que não se pode dissociar a construção e efetivação do currículo escolar da constituição histórica e social; um currículo escolar não surge sem nenhuma intencionalidade, ele é resultado de uma necessidade social e econômica.

A escola e o professor, por meio do currículo, tornam evidente as suas concepções e visões de mundo, homem, educação, concepções que podem ir de conservadoras a libertadoras, dependendo muito de qual abordagem de currículo escolar é dominante naquele contexto. Diante disso, McNeil (2001) afirma que o currículo foi construído com base nas abordagens acadêmicas, humanistas, tecnológicas e Reconstrucionista. 
No que se refere ao currículo acadêmico, podemos entender que este é o que possui maior tradição histórica. Na abordagem acadêmica defende-se uma tradição, segue a perspectiva tradicional. O seu modelo pedagógico é o empirismo, em que ideias e conceitos serão adquiridos pelas vivências, o aluno é movido a fazer atividades de tentativas e erros, até que ele obtenha uma experiência e consiga resolver de fato a atividade.

Um dos principais teóricos do empirismo foi John Locke, que defendia que o aluno era uma folha rasa, uma folha em branco, no qual se podia depositar os conteúdos e o conhecimento era desenvolvido pela atividade mental e as práticas curriculares e conhecimentos deviam ser transmitidos às novas gerações, com o objetivo de manter a ordem e o progresso da sociedade. A escola não era um espaço democrático, onde não se permitia um questionamento, uma reflexão, uma interdisciplinaridade.

Baseava-se o método didático na estruturação lógica dos conteúdos escolares. Ao entrar em sala, o professor recordava o que foi discutido anteriormente. Apresentava um novo tema, trabalhava a aplicabilidade dos conhecimentos vistos com exemplos, usando os exemplos padrões, permitindo a aplicação do que foi dito. Havia a aplicação de exercícios com reprodução fiel do conteúdo. Nessa perspectiva, o professor não mudava o seu tipo de metodologia, se o aluno não conseguia se encaixar, ou ele trabalhava a respeito disso, ou ele acabava saindo desse tipo de escola, o professor jamais aceitava ser questionado e apenas passava os conteúdos, sem uma contextualização histórica e cultural acerca de diversas situações. Nesse tipo de currículo, não ocorria a interdisciplinaridade.

A avaliação era uma verificação dos conteúdos apreendidos com o decorrer das 
atividades propostas pelo professor, era sempre baseada em termos de quantidade e exatidão de raciocínio. O educador nesta abordagem teórica trabalhava com o intuito de fazer o seu aluno aprender, sem de fato ter uma mediação crítica e consciente. A finalidade da educação estava na transmissão dos conhecimentos como uma verdade absoluta, sem questionamentos, para formar indivíduos que soubessem cumprir os seus papéis na sociedade, indivíduos passivos e neutros, com apenas conhecimentos científicos, a fim de produzir dentro da sociedade, e ajudar a manter a ordem social.

Segundo contribuiç̧̃̃es de McNeil (2001), a finalidade da educação, nessa concepção teórica de currículo, era baseada sempre na transmissão dos conhecimentos que pela humanidade não eram questionados, tornando-se uma verdade absoluta. O ambiente escolar estava vinculado a manter a ordem e o raciocínio de seus alunos, a fim de serem proveitosos para todo o processo.

No que se refere ao currículo humanista que tinha como base princípios da Escola Nova, defendia a autonomia do pensar. O modelo pedagógico dessa abordagem, segundo McNeil (2001), era o construtivismo, e um dos principais teóricos desta perspectiva foi Jean Piaget. Esse currículo escolar defendia a relação entre sujeito e objeto, na qual seu conhecimento era constituído na interação entre sujeito e objeto. Quanto mais desenvolvimento, mais aprendizagem haveria.

A concepção do mundo presente no currículo humanista era construída a partir das percepções e experiências, os indivíduos assumiam a responsabilidade das decisões pessoais, e se tornava um sujeito único em processo contínuo de descoberta de seu próprio "eu", pois acreditava-se que o ser humano tinha diversas potencialidades para serem descobertas, e por meio da mediação do professor, este poderia fazer o processo de vir a ser. Nessa teoria os indivíduos não nasciam com um 
fim determinado, estavam relacionados aos ideais de crescimento, de realização própria, em que só o aluno era capaz de avaliar o que aprendeu.

Outra abordagem a ressaltar se refere ao currículo tecnológico, e este tem como pressuposto o Behaviorismo. As ideias centrais que fomentam esse currículo são: a educação voltada ao interesse social, a escola como agência educacional e preparação do homem para o mercado de trabalho. A aprendizagem acaba sendo fruto de condicionamento operante, ou seja, o comportamento é premiado, reforçado, até que ele seja condicionado de tal forma que ao se retirar o reforço o comportamento continue a acontecer. É um comportamento adquirido de forma mecânica e automática por meio de estímulos e respostas (MCNEIL, 2001).

O professor apresenta objetivos bem definidos e os planos eficientes para que as metas sejam alcançadas, aplica um reforço positivo: elogio, notas, prêmios, status etc., fortalecendo a probabilidade de o comportamento pretendido continuar acontecendo. O material didático é subdividido em pequenas etapas que favoreçam com mais frequência o feedback e, portanto, o reforço ao aluno, de maneira que ele possa utilizar sozinho, recebendo estímulos à medida que avança no conhecimento.

A educação para essa abordagem só tem sentido quando parte de uma perspectiva para a formação para o trabalho, e o professor deve executar esse currículo escolar capitalista. A avaliação feita é das competências e habilidades, indicando o comportamento e desempenho esperado. É possível constatar, até o momento, que o currículo acadêmico, humanista e tecnológico tem como pressuposto teórico e metodológico a teoria tradicional de currículo, pois pensa o processo de ensino e aprendizagem desvinculado do contexto sócio-político-econômico e cultural.

A partir da década de 1980, surgiu no Brasil uma proposta de currículo pautada 
em uma teoria crítica e esta foi denominada como reconstrucionista, tendo como pressuposto filosófico o materialismo histórico dialético. Nessa linha de pensamento a realidade é construída e reconstruída pelo homem e tem como objetivo principal a transformação social e a formação crítica do sujeito.

Sendo assim, fazia-se necessário lançar um olhar crítico dialético em relação ao contexto social e educacional, incluindo desta maneira os elementos gnosiológicos, lógicos, ontológicos e históricos, presentes nos processos de conhecimento humano. Destarte, a partir dessa perspectiva o homem se inseria no seu meio cultural de acordo com o seu contexto de sociedade, no qual o trabalho era voltado para o bem-estar da sociedade, fazendo com que o conhecimento e a educação fossem amparados sempre pela história.

De acordo com apontamentos de McNeil (2001b), o reconstrucionismo social entendia o homem e o mundo de forma interativa. A sociedade era injusta, podendo ser alienada, mas uma consciência crítica poderia ser transformada, conforme o homem entendia o contexto social, cultural, político e econômico adquiria a consciência crítica, para se assumir enquanto sujeito e único em todo o processo de sua história.

Essa base teórica acredita que o homem obtém uma capacidade de conduzir e decidir o seu próprio destino e fazer suas escolhas no decorrer de sua vida. Logo, podemos perceber o quanto a discussão acerca do currículo escolar é complexa, e requer uma intencionalidade, para que de fato seja voltada para uma sociedade emancipadora, e que obtenha uma consciência crítica para uma transformação social.

Faz-se necessário ressaltar que as abordagens curriculares podem ser classificadas sob a perspectiva de uma teoria tradicional e crítica, no que tange à 
tradicional. Os currículos acadêmico, humanista e tecnológico apresentam os processos de ensino e aprendizagem desvinculados dos aspectos sociais, evidenciando uma não relação dos conteúdos com a prática social que vise a transformação social. Já o currículo reconstrucionista, percebido por meio da teoria crítica concebe o conteúdo contextualizado, ou seja, o conhecimento só tem sentido e significado quando relacionado com a prática social. Sendo assim, não podemos ter uma visão romântica da construção do currículo pois ela é permeada de ideologias e valores, e esta concepção implicará se olharemos a sociedade, a escola e a formação humana sob um viés de reprodução ou transformação.

\section{Considerações Finais}

No decorrer das reflexões e apontamentos empreendidos neste artigo, tivemos a oportunidade de perceber o quanto a construção de um determinado currículo, é amparada por sua história e contexto social, refletindo assim em seu modo de ver, agir e pensar o mundo, seu meio cultural, político e ideológico. Para tanto, temos que compreender o conceito e o contexto do currículo escolar, podendo, assim, identificar as influências das teorias tradicionais e críticas no processo de ensino e aprendizagem.

Diante da complexidade que permeia a sociedade atual, essa discussão se faz extremamente interessante, pois, é importante refletir a respeito de qual concepção teórica permeia o currículo da escola, e o saber docente, pois desta maneira o professor poderá compreender o seu papel na educação e entender que suas ações sempre estarão voltadas a uma determinada condição social e cultural. Assim, entendemos que a compreensão do currículo escolar é fruto de diferentes contextos 
sociais, concepções políticas e ideológicas que irão nortear o modo como a escola compreende o mundo e a formação humana.

Refletir sobre currículo exige entendê-lo como uma construção e uma invenção social, o que torna necessário analisar os valores e os interesses sociais que levam à inclusão e à exclusão de determinados conhecimentos nos processos de escolarização. Em suma, não se pode pensar em uma proposta de currículo escolar sem a intencionalidade dos envolvidos no processo educacional e cientes do contexto social em que estão inseridos, pois este é elaborado tendo como premissa os aspectos sociais, políticos, econômicos, culturais e de formação humana, de acordo com o seu tempo histórico.

\section{Referências}

BAUMAN, Z. Vida líquida. Rio de Janeiro: Jorge Zahar, 2007.

COMTE, A. Écrits de jeunesse: 1816-1828. Paris: Mouton La Haye, 1970.

DEWEY, J. Reconstrução em filosofia. São Paulo: Nacional, 1959.

DURKHEIM, E. A educação moral. Petrópolis: Vozes, 2008.

GOODSON, I. F. Currículo: teoria e história. Petrópolis: Vozes, 1995

MARTINS, J. S. Anotações em torno do conceito de Educação para Convivência com o Semi-Árido. In: Educação para a convivência com o Semi-Árido Brasileiro: reflexões teórico práticas. Bahia: Juazeiro: Selo Editorial RESAB, 2004. p. 35-36.

MCNEIL, J. D. Curriculum: a comprehensive introduction. Tradução: José Camilo dos Santos Filho. Campinas: Unicamp, 2001b. 
MCNEIL, John. 0 currículo escolar reconstrucionista social. Tradução: José Camilo dos Santos Filho. Campinas: Papirus, 2001.

MOREIRA, A.F. B. (org.). Currículos e programas no Brasil. Campinas: Papirus, 1990.

MOREIRA; SILVA, T. T. (org.). Currículo, cultura e sociedade. 2. ed. São Paulo: Cortez, 1997.

SACRISTÁN, J. G. Poderes instáveis em educação. Tradução: Beatriz Affonso Neves. Porto Alegre: Artmed, 1999.

YOUNG, M. Para que servem as escolas? In: PEREIRA, M. Z. C.; CARVALHO, M. E. P.; PORTO, R. C. C. (org.). Globalização, interculturalidade e currículo escolar na cena escolar. Campinas: Alínea, 2009. p. 37-54.

Enviado em: $15 / 10 / 2018$

Aprovado em: 01/08/2019 